\title{
Rancang Bangun Monitoring Lokasi Pesawat Menggunakan ADS-B dengan RTL-SDR dan Raspberry Pi
}

\author{
M. Yoga Azto Diraputra \\ Jurusan Teknik Elektro, \\ Program Studi Teknik \\ Telekomunikasi D IV \\ Politeknik Negeri Sriwijaya \\ Palembang, Indonesia \\ yogadiraputra12@gmail.com
}

\author{
Sopian Soim \\ Jurusan Teknik Elektro, \\ Program Studi Teknik \\ Telekomunikasi D IV \\ Politeknik Negeri Sriwijaya \\ Palembang, Indonesia \\ sopiansoim@gmail.com
}

\author{
Sarjana \\ Jurusan Teknik Elektro, \\ Program Studi Teknik \\ Telekomunikasi D IV \\ Politeknik Negeri Sriwijaya \\ Palembang, Indonesia \\ sarjana@polsri.ac.id
}

\begin{abstract}
Automatic Dependent Surveillance Broadcast (ADS-B) is a surveillance technology that provides information on aircraft in the air in the form of 24 bit ICAO aircraft address, ident or squawk, massage, altitude, nationality, speed, longitude, track and heading. The problem faced now is that surveillance can only be done with a web and android-based application on FlightRadar24 so that if the user wants to display more aircraft information, the user is required to pay a subscription. To overcome this problem, hardware is needed that can receive ADS-B signals with a frequency of $1090 \mathrm{MHz}$ and can translate them into information signals. RTL-SDR is hardware that can receive signals with a frequency range from $25 \mathrm{MHz}$ - $1700 \mathrm{MHz}$, by applying the Raspberry Pi it is used to configure RTL-SDR as a receiver capable of receiving information from ADS-B signals. To get the maximum reception, an omnidirectional antenna is needed that can receive signals from all directions. With this system, it is expected to make it easier to monitor aircraft in real time and processing ADS-B signal data is determined by the strength and weakness of the signal that can be received by RTL-SDR.
\end{abstract}

Keywords- Automatic Dependent Surveillance Broadcast, RTL-SDR R820T2, Antena, Raspberry Pi

\section{PENDAHULUAN}

Teknologi radar merupakan teknologi yang digunakan untuk mendeteksi, mengukur jarak sebuah pesawat, salah satunya digunakan hampir semua di setiap bandar udara. Namun teknologi radar sekarang mulai digantikan dengan sistem ADS-B (Automatic Dependant Surveilance - Broadcast)[1].

Automatic Dependant Surveilance - Broadcast adalah sebuah teknologi baru sistem pemantauan yang digunakan untuk memberikan informasi pesawat di udara yang dimana sistem avionic dari pesawat terbang memberikan informasi dengan kombinasi Global Positioning System, sehingga pesawat bisa terlacak yang dimana pengiriman data penerbangan dilakukan secara otomatis[2].
Salah satu permasalah yang dihadapi dalam perkembangan teknologi ADS-B yaitu bagaimana cara mendeteksi dan memonitoring pesawat udara dengan peralatan yang murah dan praktis dibanding peralatan ADS-B di bandara[3]. Sedangkan untuk masyarakat awam sendiri, pemantauan penerbangan dapat diakses secara mudah menggunakan aplikasi berbasis web dan android di FlightRadar24, hanya saja aplikasi ini memiliki beberapa kekurangan, di antaranya adalah jika pengguna ingin menampilkan informasi pesawat lebih banyak, pengguna diharuskan membayar secara berlangganan, dan juga terdapat delay yang terjadi karena pemrosesan data yang dibutuhkan.

Sinyal ADS-B berfrekuensi $1090 \mathrm{MHz}$ dengan cakupan maksimum pancaran ke Ground Statiton ADS-B hingga $200 \mathrm{NM}(370 \mathrm{~km})$. Untuk dapat menerima data sinyal yang berfrekuensi $1090 \mathrm{MHz}$ serta menterjemahkannya, maka diperlukan perangkat SDR (Software Defined Radio) [4]. Saat ini sudah tersedia hardware SDR yang jauh lebih praktis dan harga terjangkau yang dinamakan RTL-SDR, yang dilengkapi chipset Realtek R820T2 yang mampu menangkap sinyal radio dari frekuensi tertentu. Pada penelitian - penelitian yang dilakukan sebelumnya, terdapat masih banyak kekurangan seperti jarak jangkauan receiver dapat menerima sinyal kurang jauh, data parameter ADS-B yang masih kurang, dan tidak maksimal.

Rancangan sistem monitoring ini akan dibuat sistem reicever sinyal ADS-B menggunakan RTLSDR R820T2 dan penambahan antena omnidirectional yang berfungsi sebagai penerima sinyal yang telah di broadcast oleh pesawat. Sistem tersebut memerlukan aplikasi dump1090 dan Pi Aware untuk menampilkan data sinya $1090 \mathrm{MHz}$ dari target yang diproses di RTL-SDR.

\section{DASAR TEORI}

A. ADS-B (Automatic Dependent SurveillanceBroadcast)

Automatic Dependent Surveillance-Broadcast adalah sebuah sistem surveillance dengan dilengkapi sebuah transponder yang dapat mengirimkan data penerbangan secara otomatis. Data penerbangan diperoleh dari sistem navigasi satelit GNSS (Global 


\section{Rancang Bangun Monitoring Lokasi Pesawat Menggunakan ADS-B dengan RTL-SDR dan Raspberry Pi}

Navigation Satellite System). Selanjutnya Data Pesawat dikirimkan ke display ATC digunakan untuk dalam memonitoring pesawat terbang. ADS-B menyediakan dua layanan utama dalam TIS-B (Traffic Information Services-Broadcast) yang menyediakan informasi tentang lalu lintas udara dan FIS-B (Flight Information Services-Broadcast) yang dimana menyediakan informasi melalui peringatan cuaca dengan frekuensi $1090 \mathrm{MHz}$ [5].

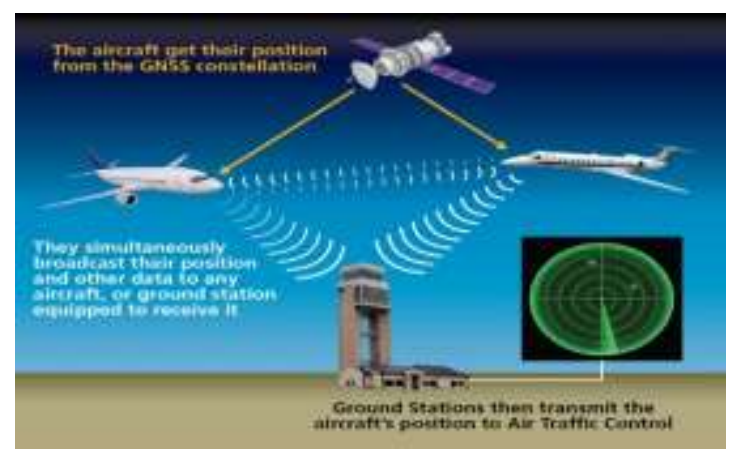

Gambar 1. Prinsip Kerja ADS-B

\section{B. Raspberry Pi}

Raspberry Pi adalah papan tunggal single-board circuit yang menggunakan sistem operasi berbasis Linux yang mana dengan sistem operasi ini dapat bebas bereksperimen atau membuat project yang lebih kompleks dan dapat hubungkan dengan mouse, keyboard, dan monitor untuk difungsikan sebagai PC desktop[6].

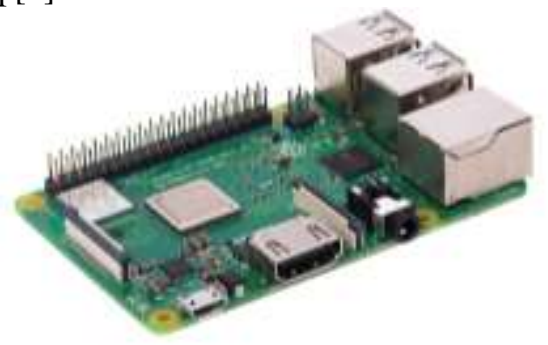

Gambar 2. Raspberry Pi

\section{Software Defined Radio}

Software Defined Radio (SDR) adalah sebuah teknologi yang dikembangkan untuk membangun sistem komunikasi radio yang fleksibel dimana kompenen berupa hardware diatur oleh software komputer[7].

RTL-SDR R820T2 adalah salah satu jenis Software Defined Radio yang berperan sebagai reicever. Dongle berbasis Chipset Realtek R820T2 yang mampu menerima signal radio dari frekuensi 25 MHz sampai $1700 \mathrm{MHz}$.

RTL-SDR dapat digunakan untuk scanner radio pita lebar, mendengarkan percakapan yang tidak terenskripsi yaitu polisi, ambulance, pemadam kebakaran dan satelit.

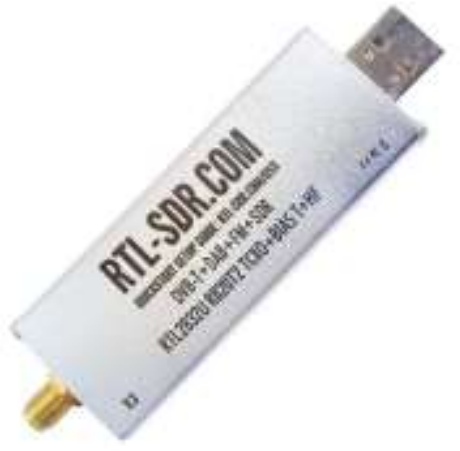

Gambar 3. RTL-SDR R820T2

D. Antena Omnidircetional

Antena omnidirectional Antena omnidirectional didefenisikan sebagai saluran transmisi dengan pancaran sinyal ke segala arah dengan daya sama. Saluran transmisi tersebut digunakan untuk mengubah gelombang elektromagnetik di udara menjadi gelombang listrik.

Antena omnidirectional yang digunakan pada rancangan ini menggunakan kabel coaxial Rg-06 dengan faktor kecepatan $85 \%$ dengan panjang yang mengikuti panjang gelombang yang telah ditentukan dengan rumus yang sudah di tetapkan dalam perhitungan antena[8].

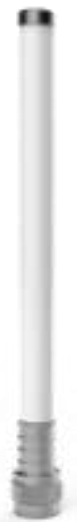

Gambar 4. Antena Omnidirectional

\section{E. Dump 1090}

Dump1090 merupakan software monitoring pesawat yang dikombinasikan dengan RTL-SDR yang biasanya digunakan untuk decoding ADS-B. Dump1090 jika dijalankan di Raspberry Pi, maka akan mengubah seluruh Pi menjadi pemroses data ADS-B. Dump1090 sangat kuat dan pandai mendekode sinyal lemah.

\section{F. PiAware}

PiAware adalah aplikasi monitoring pesawat berbasis web yang berjalan pada Raspberry Pi untuk mengirimkan data dump1090 ADS-B dan Mode S secara aman ke FlightAware. PiAware dapat menjalankan Raspberry Pi mereka sendiri dengan penerima ADS-B dan dump1090. 


\section{Rancang Bangun Monitoring Lokasi Pesawat Menggunakan ADS-B dengan RTL-SDR dan Raspberry Pi}

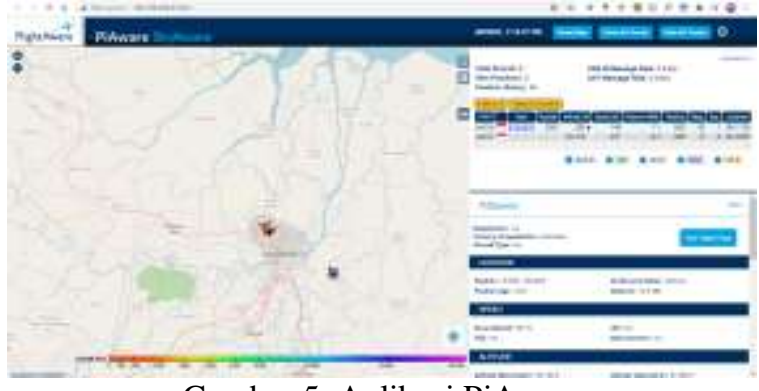

Gambar 5. Aplikasi PiAware

\section{METODE PENELITIAN}

A. Kerangka Penelitian

Kerangka penelitan terdiri dari beberapa tahapan. Bentuk diagram keseluruhan pada tahapan penelitian ini akan menghasilkan suatu sistem yang dapat bekerja dengan baik.

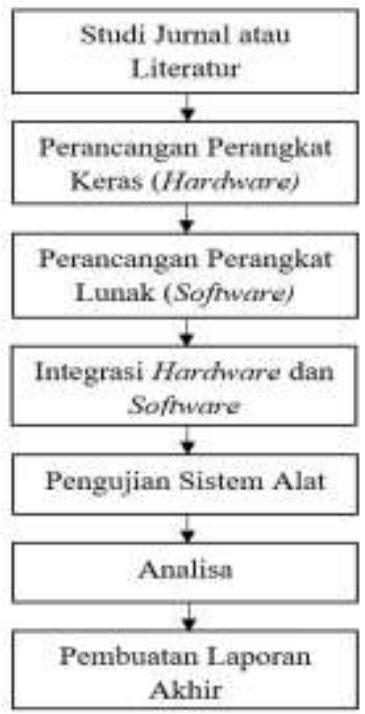

Gambar 6. Kerangka Penelitian

1. Studi Jurnal atau Literatur

Pada Studi Jurnal atau literatur adalah tahapan pertama yang dilakukan untuk menyelesaikan masalah yang ada. Studi literatur dilakukan dengan cara menelusuri sumber-sumber penelitian sebelumnya, baik dari buku, jurnal terakreditasi, maupun internet. Pada tahap ini diketahui masalah pada ADS-B, mulai dari pemeliharaan yang rutin dan banyak menghabiskan biaya. Maka dari itu dengan studi literature, dapat dilakukan pembaharuan penelitian sebelumnya.

2. Perancangan Perangkat Keras (Hardware) Pada tahapan ini, perancangan perangkat keras merupakan perancangan perangkat yang akan dibuat sesuai dengan kebutuhan alat. Komponen yang digunakan harus diperhatikan untuk menghindari terjadinya kerusakan saat pengujian sistem. Komponen tersebut seharusnya memiliki karakteristik yang sesuai dengan kebutuhan pembuatan alat. Pada rancangan perangkat keras digunakan RTL-SDR R820T2 sebagai receiver untuk menirma sinyal dengan cakupan yang cukup luas, dengan menambahkan antena coaxial linear diharapkan agar mendapatkan hasil kinerja rancangan receiver yang maximal. Perancangan perangkat keras tersebut dapat dilihat pada diagram dibawah ini.

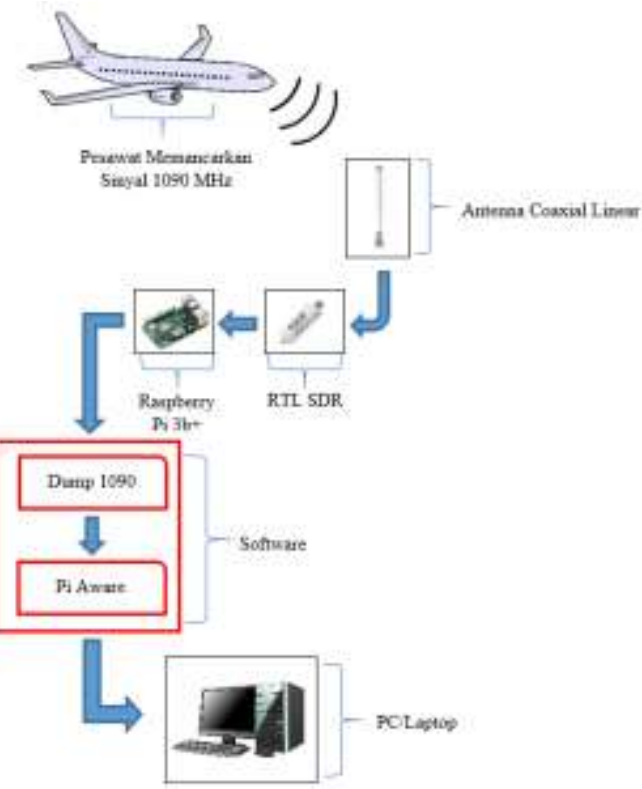

Gambar 7. Perancangan Perangkat Keras

3. Perancangan Perangkat Lunak

Pada tahapan ini, perancangan perangkat lunak (software) yang akan dilakukan untuk mengontrol sistem dan pengolahan matematis dari keseluruhan program. Sistem receiver sinyal dirancang agar dapat mengolah sinyal ADS-B menjadi informasi, software yang digunakan antara lain Dump 1090 sebagai penampung data sinyal yang diperoleh dan juga Pi Aware sebagai monitoring lokasi pesawat yang telah diterjemahkan dalam bentuk Map. Berikut merupakan diagram perancangan perangkat lunak.

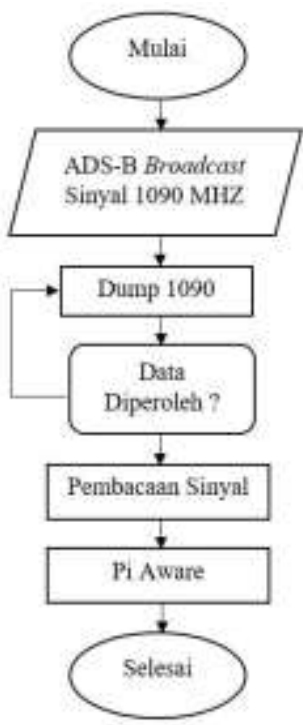

Gambar 8. Diagram Perangkat Lunak 


\section{Rancang Bangun Monitoring Lokasi Pesawat Menggunakan ADS-B dengan RTL-SDR dan Raspberry Pi}

4. Integrasi Hardware dan Software

Pada tahap ini, dimana hardware dan software digabungkan sehingga dapat terintegrasi dengan baik.

5. Pengujian Sistem Alat

Pada pengujian sistem alat secara keseluruhan untuk mengetahui dan menguji alur sistem penangkapan sinyal ADS-B menggunakan RTLSDR yang sudah terintegrasi dari alat yang telah dibangun. Parameter yang akan diujikan meliputi data informasi pesawat 24 bit ICAO aircraft address, Nationality, Ident atau Squawk, Altitude, Message, Longitude, Speed, Heading dan Track dengan menggunakan Pi Aware yang teintegrasi dengan Dump 1090.

6. Analisa

Pada bagian ini, dilakukan analisa terhadap alat yang telah selesai dibuat dan diuji sebelumnya.

7. Pembuatan Laporan Akhir

Pada tahap terakhir, dimana akan dibuat laporan dan dirangkum secara keseruluhan tentang aspek yang ada pada penelitian serta dijelaskan secara singkat dan jelas.

\section{HASIL DAN PEMBAHASAN}

A. Pengaturan Perangkat Lunak (Software)

Instalasi Dump 1090 Instalasi Dump 1090 bertujuan agar RTL-SDR dapat mendecoding ADS-B.

a) Hubungkan RTL-SDR pada Raspberry Pi.

b) Install file dump1090 di Raspberry Pi untuk mendownload driver.

c) Buka file dump1090, kemudian klik start. Jika berhasih maka akan muncul tampilan berikut

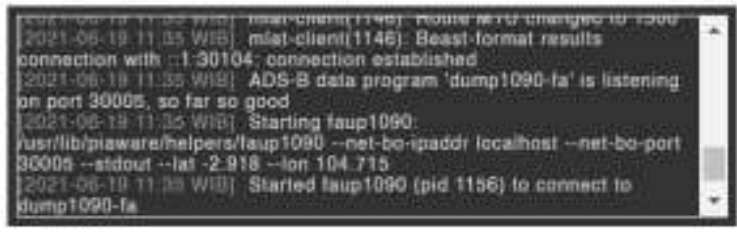

Gambar 9. Tampilan Dump1090 yang berhasil connected

Pengaturan Pi Aware

a) Hubungkan RTL-SDR pada Raspberry Pi.

b) Install Pi Aware di Raspberry Pi

c) Jika selesai, masuk ke situs website Pi Aware dan kemudian klik registrasi akun.

d) Setelah registrasi, masuk menggunakan akun yang telah didaftarkan, kemudian klik join.

e) Setalah join, klik My ADS-B, maka akan terbuka tampilan informasi ADS-B anda.

f) Jika Pi Aware, Flight Aware, dan MLAT sudah berwarna hijau, maka monitoring pesawat sudah siap dijalankan, lalu klik view live data. Maka akan muncul tampilan berikut.

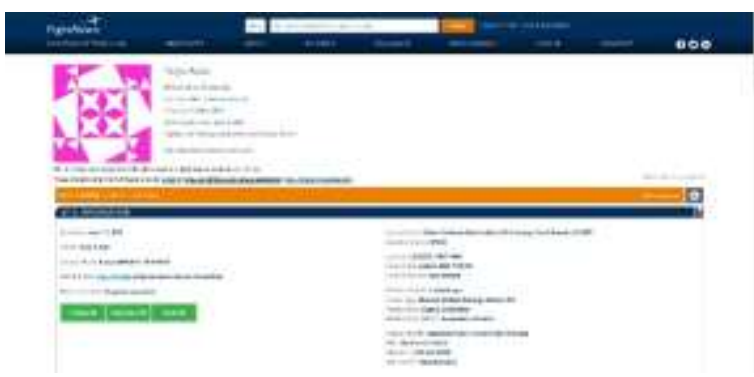

Gambar 10. Tampilan Pi Aware yang sudah terhubung ke RTL-SDR dan siap dijalankan.

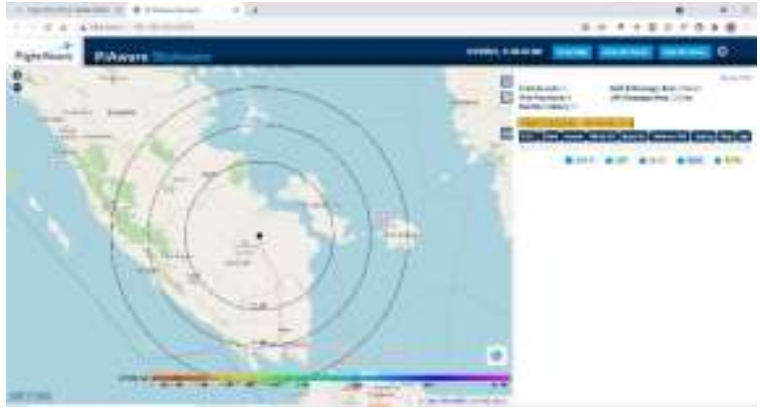

Gambar 11. Tampilan Maps Pi Aware yang siap dilacak

B. Perancangan Perangkat Keras (Hardware) Perancangan Antena Omnidirectional

Pada perancangan perangkat keras antena omnidirectional ini bahan utama yang digunakan adalah kabel coaxial Rg-06 (75 Ohm / 50 Ohm) yang memiliki velocity factor kecepatan sebesar $84 \%$.

Rumus perhitungan panjang elemen:

$$
\begin{aligned}
& \chi=C / f \\
& \mathrm{~L}=0.5 \times k \times \chi
\end{aligned}
$$

$f=$ Frekuensi kerja yang digunakan

$\chi=$ Panjang gelombang

$C=$ Cepat rambat cahaya $\left(3 \times 10^{8} \mathrm{~m} / \mathrm{s}\right.$ atau

$30000000 \mathrm{~m} / \mathrm{s}$ )

$\mathrm{L}=$ Panjang elemen

$\mathrm{K}=$ Velocity factor $(0,84)$

Jadi cepat rambat sinyal pada kabel adalah $300000000 \mathrm{~m} / \mathrm{s} \times 84 \%$

$\chi=C / f=30000000 / 1090000000$

Panjang elemen yang digunakan yaitu;

$\mathrm{L}=0.5 \times k \times \chi$

$=0,5 \times 0,84 \times 30000000 / 1090000000$

$=11,6 \mathrm{~cm}$

Jadi panjang elemen coaxial yang diperlukan masing masing adalah $11,6 \mathrm{~cm}$ 


\section{Rancang Bangun Monitoring Lokasi Pesawat Menggunakan ADS-B dengan RTL-SDR dan Raspberry Pi}

Pada perancangan antena omnidirectional kali ini tiap- tiap elemen yang digunakan sebanyak 8 buah dengan panjang masing- masing telemen adalah 11,6 $\mathrm{cm}$.

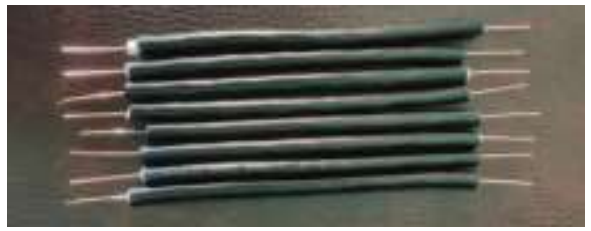

Gambar 12. Panjang Tiap elemen antena yang telah dipotong menjadi 8 bagian
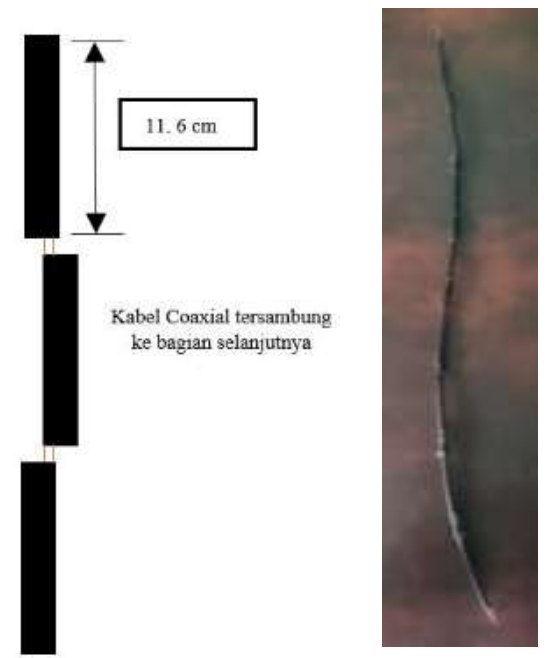

Gambar 13. Penyambungan tiap elemen antena

Perancangan Perangkat Keras Secara Keseluruhan

Pada perancangan hardware receiver sinyal ADS-B yang telah dibuat sesuai rancangan alat, sehingga hasil tersebut dapat terintegrasi dengan software.

Berikut merupakan hasil dari perancangan perangkat keras (hardware) secara keseluharan pada gambar berikut.

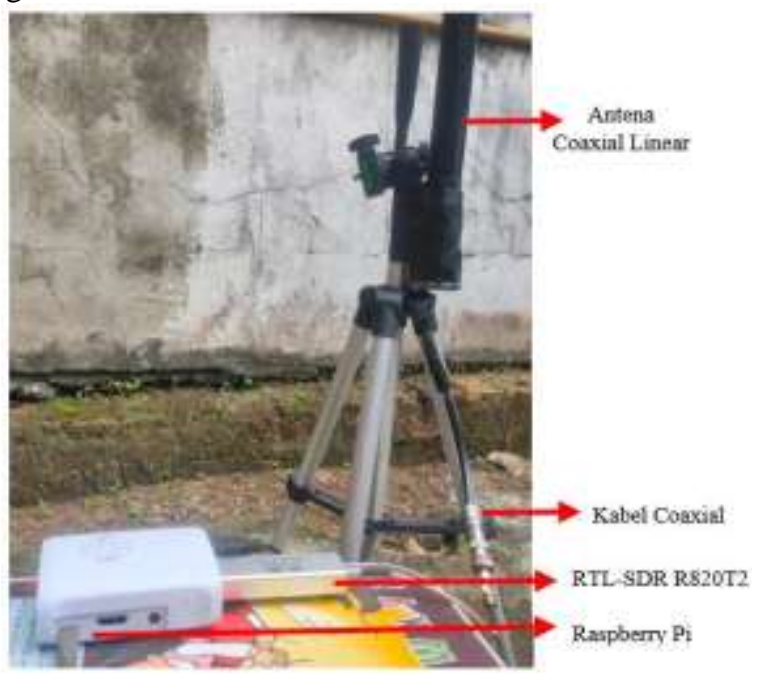

Gambar 14. Tampilan rancangan perangkat keras

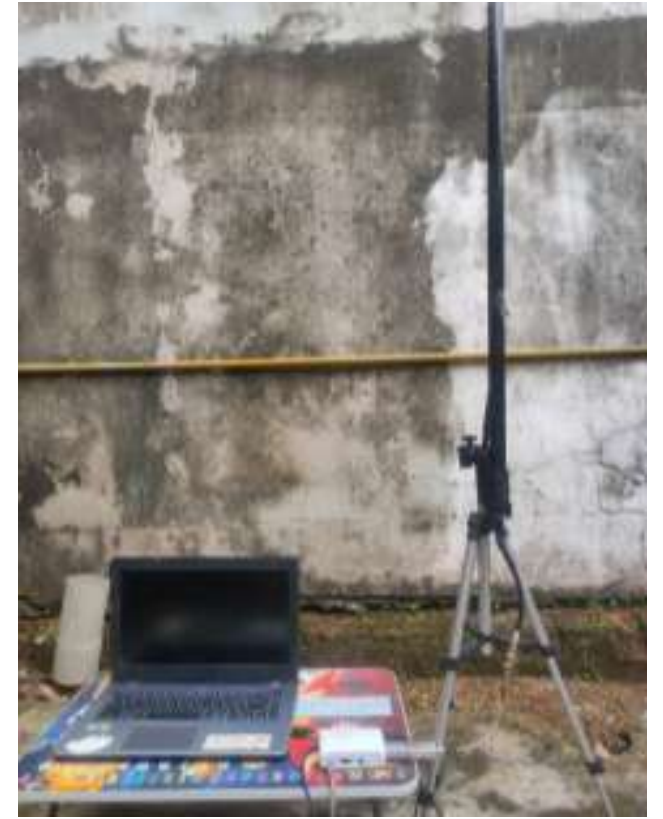

Gambar 15. Hasil rancangan perangkat keras secara keseluruhan

\section{Hasil Pengujian}

Pada tahap ini, dimana RTL-SDR dan rancangan antenna omnidirectional dihubungkan ke Raspberry Pi dengan power 220v dan beberapa software yang telah diinstall diantaranya Dump1090 dan Pi Aware. Pada kali ini dilakukan 2 tahap pengujian perancangan ADS-B, yaitu pada siang hari dan malam hari pada hari dengan hasil sebagai berikut.

\section{Pengujian pada siang hari}

Pada pengujian kali dilakukan pada hari Kamis, 10 Juni 2021, pukul 13:07 WIB dengan diperoleh 3 sinyal ADS-B pesawat yang ditangkap oleh rancangan antenna, kemudian diterjemahkan sinyal tersebut menjadi data informasi sebagai berikut.

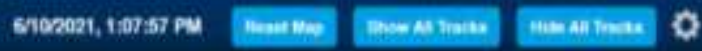

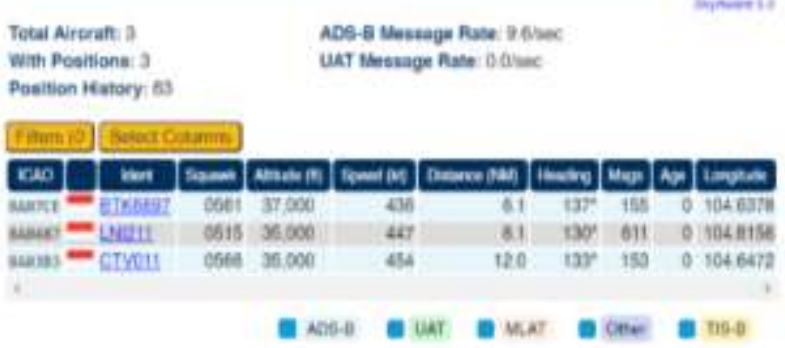

Gambar 16. Data sinyal yang diterjemahkan menjadi informasi pada siang hari 


\section{Rancang Bangun Monitoring Lokasi Pesawat Menggunakan ADS-B dengan RTL-SDR dan Raspberry Pi}

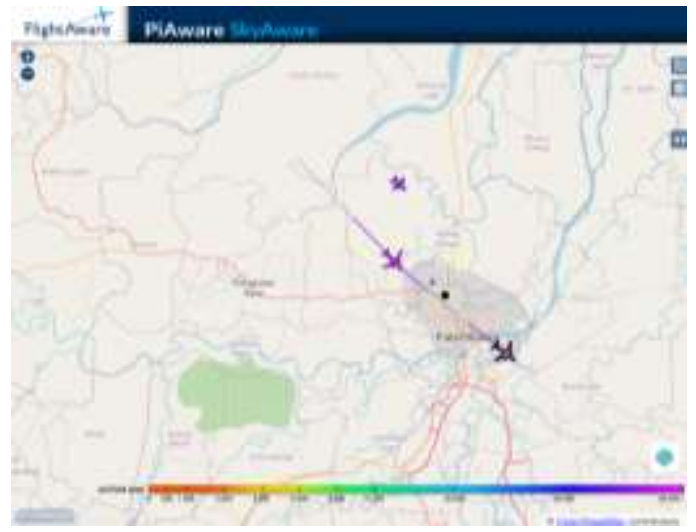

Gambar 17. Data dalam bentuk map pada siang hari

Data sinyal yang diterjamahkan menjadi informasi yang didapat pada siang hari dari salah satu pesawat sebagai berikut.

Tabel 1. Data informasi salah satu pesawat

\begin{tabular}{|l|l|}
\hline \multicolumn{1}{|c|}{ Parameter } & \multicolumn{1}{c|}{ Informasi } \\
\hline ICAO24 & 8 A07CE \\
\hline Identity & BTK6897 \\
\hline Nation & Indonesia \\
\hline Altitude & $37000 \mathrm{ft}$ \\
\hline Longitude & $104.6378^{\circ}$ \\
\hline Speed & $436 \mathrm{kts}$ \\
\hline Heading & $137^{\circ}$ \\
\hline Message & 155 \\
\hline
\end{tabular}

2. Pengujian pada Malam hari

Pada pengujian kali dilakukan pada hari Senin, 8 Juni 2021, pukul 19:17 WIB dengan diperoleh 2 sinyal ADS-B pesawat yang ditangkap oleh rancangan antenna, kemudian diterjemahkan sinyal tersebut menjadi data informasi sebagai berikut.

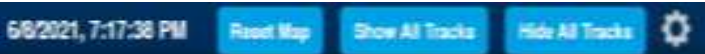

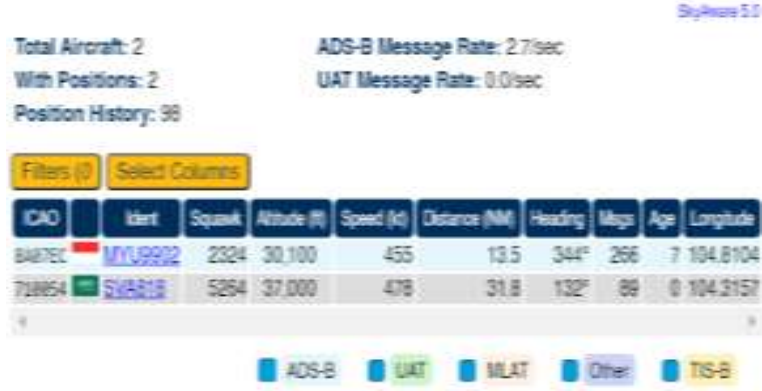

Gambar 18. Data sinyal yang diterjemahkan menjadi informasi pada malam hari

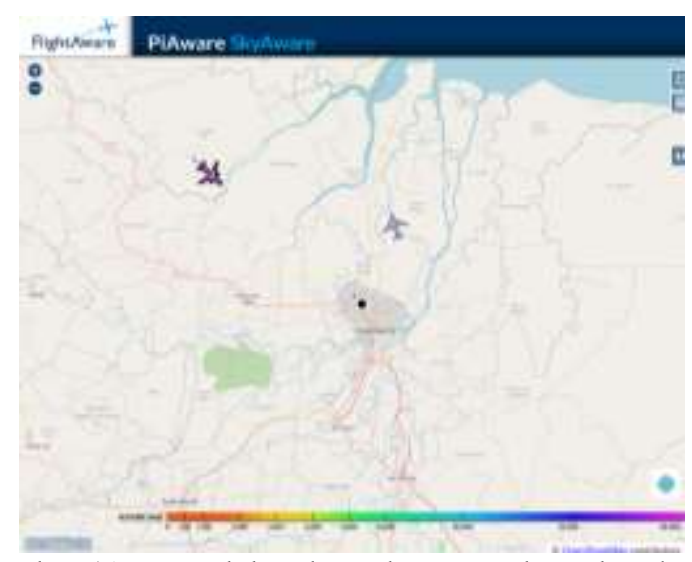

Gambar 19. Data dalam bentuk map pada malam hari

Data sinyal yang diterjamahkan menjadi informasi pada malam hari yang didapat dari salah satu pesawat sebagai berikut.

Tabel 2. Data informasi salah satu pesawat

\begin{tabular}{|l|l|}
\hline \multicolumn{1}{|c|}{ Parameter } & \multicolumn{1}{c|}{ Informasi } \\
\hline ICAO24 & 710054 \\
\hline Identity & SVA816 \\
\hline Nation & Saudi Arabia \\
\hline Altitude & $37000 \mathrm{ft}$ \\
\hline Longitude & $104.3157^{\circ}$ \\
\hline Speed & $478 \mathrm{kts}$ \\
\hline Heading & $137^{\circ}$ \\
\hline Message & 89 \\
\hline
\end{tabular}

\section{KESIMPULAN}

Berdasarakan hasil rancangan yang telah dibuat untuk menerima sinyal ADS-B pesawat dapat disimpulkan bahwa, rancangan receiver sinyal ADS-B ini menggunakan RTL-SDR yang dimana sebagai penangkapan sinyal pesawat ADS-B 1090 Mhz Serta dibutuhkan Antena Coaxial Collinear agar hasil yang di dapatkan secara maximal, dan untuk Software nya digunakan Dump1090 yang berfungsi sebagai penerjemah sinyal ADS-B 1090 Mhz serta Pi Aware yang fungsinya sebagai monitoring lokasi pesawat yang telah diterjemahkan oleh Dump1090 Mhz. Integrasi antara hardware dan software pada rancang bangun sistem monitoring lokasi sinyal ADS- B pesawat menghasilkan informasi berupa 24 bit ICAO aircraft address, ident atau squawk, massage, altitude, nationality, speed, longitude, track serta heading.

\section{DAFTAR PUSTAKA}

[1] Yati,N. dan Susanti. (2014) "WARTA ARDHIA Jurnal Perhubungan Udara: Implementasi Automatic Dependent Surveillance Broadcast (ADS-B) di Indonesia" Vol. 40:147-162.

[2] Pusat teknologi Elektronika. (2018). "Automatic Dependent Surveillance- Broadcast (ADS-B)". https://pte.bppt.go.id/tentangkami/portofolio/auto matic- dependent-surveillance-broadcast-ads-b. [online, diakses 16 Maret 2021]. 


\section{Rancang Bangun Monitoring Lokasi Pesawat Menggunakan ADS-B dengan RTL-SDR dan Raspberry Pi}

[3] Ma'ruf. Sistem Pengawasan Angkutan udara Perintis Berbasis ADS-B. Jakarta: Badan Penelitian dan Pengembangan Kementrian Perhubungan. 2016: 227-228.

[4] Nasron, Nasron, Martinus Mujur Rose, and Darin Fadhilah. "Pengembangan Server VOIP Menggunakan FREEPBX Dan Asterisk Berbasis Raspberry PI." PROtek: Jurnal Ilmiah Teknik Elektro 8.1 (2021): 22-25.

[5] Pusat teknologi Elektronika. (2018) "Automatic Dependent Surveillance- Broadcast (ADS-B)" [online, diakses 28 Februari 2021]. https://pte.bppt.go.id/berita/91-sistempemantaupenerbangan-nir-radar-berbasis-ads-bautomatic-dependent-surveillance-broadcast-2

[6] Satya Narayana, P., Syam Kumar, M.N.V.S., Keerthi Kishan, A., Suraj, K.V.R.K."Design approach for wideband FM receiver using RTLSDR and raspberry PI" International Journal of Engineering and Technology (UAE), 7 (2), pp. 9- 12, 2018

[7] Bagus, Bambang et.all. (2019) "Studi Ekperimental Penerima ADS-B Menggunakan RTL 1090 dan RTLSDR R820T2 di Bandara Juanda Surabaya".

[8] Sohibi, M. Denni dan Lasmadi. (2020). “ Rancang Bangun Receiver menggunakan Antena $1090 \mathrm{MHz}$ dan Low Noise Amplifier untuk Menambah Jarak Jangkau Penerimaan Sinyal dan Data Parameter Target ADS-B Berbasis RTL820T2".AVITEC. Vol. 2, No. 2: halaman 129-131.

[9] Susanto, Try, and Syaiful Ahdan. "Pengendalian Sikap Lateral Pesawat Flying Wing Menggunakan Metode LQR." vol 7 (2020): 99103.

[10] Irawan, Fery, Ciksadan Ciksadan, and Suroso Suroso. "Rancang Bangun Receiver Sinyal ADSB Pesawat Menggunakan RTL-SDR serta Antena 1090 MHz." PROtek: Jurnal Ilmiah Teknik Elektro 7.2 (2020): 84-89. 